Bulletin of Pharmaceutical Sciences
Assiut University
Website: http://bpsa.journals.ekb.eg/
e-mail: bullpharm@aun.edu.eg

\title{
DEVELOPMENT AND OPTIMIZATION OF ALBENDAZOLE NANOSUSPENSION AS LOCAL ADJUVANT THERAPY FOR TREATMENT OF ENTEROBIASIS
}

\author{
Aml I. Mekkawy ${ }^{*}$, Gihan Fetih ${ }^{2,3}$, Mahmoud EL-Badry $^{2,3}$ and Ayat Allam ${ }^{2,3}$ \\ ${ }^{1}$ Department of Pharmaceutics and Clinical Pharmacy, Faculty of Pharmacy, Sohag \\ University, Sohag 82524, Egypt \\ ${ }^{2}$ Department of Pharmaceutics, Faculty of Pharmacy, Assiut University, Assiut 71526, Egypt \\ ${ }^{3}$ Assiut International Center of Nanomedicine, Al-Rajhy Liver Hospital, Assiut University, \\ Assiut, Egypt
}

\begin{abstract}
The aim was to develop an optimized albendazole (ALB) nanosuspension to improve its solubility and therapeutic activity as an adjuvant localized therapy for treatment of the pinworm infection to enhance oral treatment outcomes using Box-Behnken design. ALB-nanosuspensions were successfully prepared by antisolvent sono-precipitation technique considering amount of Lecithin, PVP and ultrasonication time as independent variables. All the formulations were characterized regarding their particle size and PDI (dependent variables).

Nanoparticle size was significantly increased by increasing lecithin and PVP concentrations while sonication time showed no influence. PDI of the nanosuspension was insignificantly decreased with increasing lecithin concentration and probe-sonication time. Optimum formulation was identified and subjected to solid phase characterization and morphological studies. ALB nanosuspension showed 10 folds increase in solubility over pure albendazole powder. Eventually, we studied the anthelmintic activity of ALB nanosuspension compared to free $A L B$ where nanosuspension treated group showed lesser paralysis and death time than free $A L B$.
\end{abstract}

\section{INTRODUCTION}

The broad spectrum anthelmintic, Albendazole (ALB), is effectively used against different intestinal and systemic parasitosis in both human and animals ${ }^{1}$. However, it has a limited efficacy following oral administration due to its low aqueous solubility that led to poor intestinal absorption ${ }^{2}$. Accordingly, higher or multiple dosing of the drug should be used to provide the required effective concentration which might cause adverse effects in some cases $^{3}$. Moreover, the poor aqueous solubility of ALB limits its formulation and administration routes ${ }^{4}$. Many researchers studied the improvement of solubility and dissolution of ALB in order to enhance its efficacy $^{5-7}$. Nanosuspension formulations of hydrophobic drugs are an attractive alternative to solve their bioavailability problems. Scaling down to nanosized particles improves drug aqueous solubility and bioavailability by increasing the surface area of the drug that comes into contact with the surrounding biological media ${ }^{8}$. Though nanosuspension increases the surface area of the particles, it provides a thermodynamically unstable system ${ }^{9}$. Therefore, stabilizers and surfactants could be used to stabilize that system by wetting the particle surface of the lipophilic drugs and provide them with steric barriers to prevent agglomeration of the nanosuspension system $^{10}$. Accordingly, addition of an appropriate stabilizer and/or surfactant with a proper concentration could be important to maintain the system stability. 
Developing a rectal delivery system may be a promising route especially for drugs with poor aqueous solubility such as ALB, over the oral administration ${ }^{11}$. Rigter et al. ${ }^{12}$ studied the bioavailability of ALB after administration of ALB-loaded macrogol suppositories. They detected no ALB or albendazole sulfoxide (ALB metabolite) concentrations in the plasma which could be due to the ALB poor water solubility or decreasing ALB absorption in the rectum neutral $\mathrm{pH}$. In order to improve its bioavailability, they suggested a more fatty suppository vehicle. Singh et al. ${ }^{13}$ studied the efficacy of local anal application of ALB to relief enterobiasis-induced pruritus ani, where study showed significant relief in a very simple type of therapy. Moreover, they recommended the local anal application of ALB in conjunction with oral anthelmintic in case of children with severe distressing pruritus ani caused by enterobiasis.

Based on the aforementioned reported data considering the usefulness of nanosuspension delivery system in improvement of bioavailability and the importance of local application of ALB in the early relief of enterobiasis-induced pruritus ani, the current study involved the preparation of an optimized ALB nanosuspension formulation using Box-Behnken design, to be applied locally for pinworm infection as a complementary treatment with the oral therapy to improve the outcome of treatment and reduce time.

\section{MATERIALS AND METHODS}

\section{Materials}

Albendazole was kindly gifted from Saudi Pharmaceutical Industries (Riyadh, Saudi Arabia). Pluronic ${ }^{\circledR}$ F68 and soya lecithin were purchased from Sigma (St Louis, MO, USA). Poly vinyl pyrrolidine (PVP; MWt 44,000) was purchased from BDH (England). Glacial acetic acid (GAA) and methanol were purchased from El Nasr pharmaceutical chemical Co. (Egypt).

\section{Methods \\ Experimental design}

Box-Behnken design with a three-levels and three-factors was applied to increase the experimental efficiency with minimal number of experiments ${ }^{14}$. This design allowed the optimization of nanosuspension formulations and study of the effects of independent variables on the dependent variables (Table 1). The independent variables were concentration of lecithin $\left(\mathrm{X}_{1}\right)$, concentration of PVP $\left(\mathrm{X}_{2}\right)$ and probe-sonication time $\left(\mathrm{X}_{3}\right)$. Other parameters, including amount of drug, concentration of Pluronic $^{\circledR}$ F86 and volumes of organic and aqueous phases, were set at fixed levels. The established dependent variables were; $\mathrm{Y}_{1}=$ mean particle size and $\mathrm{Y}_{2}=$ polydispersity index (PDI). Design-Expert ${ }^{\circledR}$ (version 10, Stat-Ease Inc. Minneapolis, MN) was used to design and analyze a series of 15 experimental runs (formulations). The data were analyzed using analysis of variance (ANOVA) and the polynomial equation was statistically evaluated by finding the statistical significance of coefficients $(p<0.05)$. Statistical evaluation of

Table 1: Dependent and independent variables and their levels for the Box-Behnken design.

\begin{tabular}{||l|c|c|c|}
\hline \multicolumn{1}{|c|}{ Factors } & \multicolumn{3}{c|}{ Levels of variables } \\
\hline Independent Variables & Low (-1) & Medium (0) & High (+1) \\
\hline $\mathrm{X}_{1}=$ Amount of lecithin (\%) & 0 & 0.25 & 0.5 \\
\hline $\mathrm{X}_{2}=$ Amount of PVP (\%) & 0 & 0.25 & 0.5 \\
\hline $\mathrm{X}_{3}=$ Ultrasonication time (min.) & 7 & \multicolumn{3}{|c|}{ Constraints } \\
\hline Dependent variables (Responses) & \multicolumn{3}{|c|}{ Minimum } \\
\hline $\mathrm{Y}_{1}=$ Average particle size & \multicolumn{3}{|c|}{ Minimum } \\
\hline $\mathrm{Y}_{2}=$ Poly dispersity index & \multicolumn{3}{|c|}{} \\
\hline
\end{tabular}


the best-fitting experimental model (linear, two-factor interaction, quadratic, and cubic models) was performed according to multiple correlation coefficient $\left(\mathrm{R}^{2}\right)$ provided by Design-Expert $^{\circledR}$ software. Response surface plots such as contour and 3D surface were used to elucidate the relationship between dependent and independent variables.

\section{Preparation of albendazole nanosuspensions}

ALB nanosuspensions were prepared using sono-precipitation method. An accurately weight amount of ALB (20 mg) was dissolved in GAA (4\% v/v) and $5 \mathrm{ml}$ methanol to form an organic solution. The antisolvent phase (aqueous phase) was prepared by dissolving a previously calculated different concentrations of soya lecithin and PVP in water according to the above-mentioned experimental design. Organic solution was injected dropwise into 10 $\mathrm{ml}$ aqueous phase under intense stirring followed by sonication using a Cole Parmer ultrasonic processor (Vernon Hills, IL) for previously determined different time lengths.

\section{Optimization and characterization of albendazole nanosuspensions}

In order to get the optimum values of the studied variables, graphical and numerical analyses were performed by Design-Expert ${ }^{\circledR}$ software version 10 based on the criteria of desirability. Data were analyzed using analysis of variance to identify the significance effects of the studied factors on response regression coefficients.

\section{Particle Size measurement}

The mean particle size and PDI of ALB nanosuspensions were measured by dynamic light scattering using Zetasizer (Nano ZS90, Malvern Instruments, UK). In brief, about 100 $\mu \mathrm{L}$ of the prepared nanosuspension were diluted using double distilled water to reach 1 $\mathrm{ml}$ final volume. All the samples were analyzed in triplicate and data were represented in mean \pm SD.

\section{Saturation solubility ${ }^{15}$}

Solubility of the optimized ALB nanosuspension was measured compared to solubility of pure ALB powder. Excess powder of each sample was added into screw-capped vial containing $10 \mathrm{ml}$ phosphate buffer $(\mathrm{pH}$ 7.4). Vials were then shaken for $48 \mathrm{hrs}$ in a mechanical shaker at $37^{\circ} \mathrm{C}$ and then allowed to settle down. After that, dispersions were filtered, diluted and analyzed for drug content using UV-visible spectrophotometer (Jenway 6305 , UK) at $\lambda_{\max } 300 \mathrm{~nm}$ using a predetermined calibration curve.

\section{Scanning electron microscopy (SEM)}

The surface morphology of the optimized ALB nanosuspension was examined using scanning electron microscope (Hitachi, Japan). Briefly, nanosuspension was diluted with double distilled water (100 time) and a drop was placed on sample holder, air dried and coated with gold and palladium. Finally, images were captured using the SEM (Fig. 1).

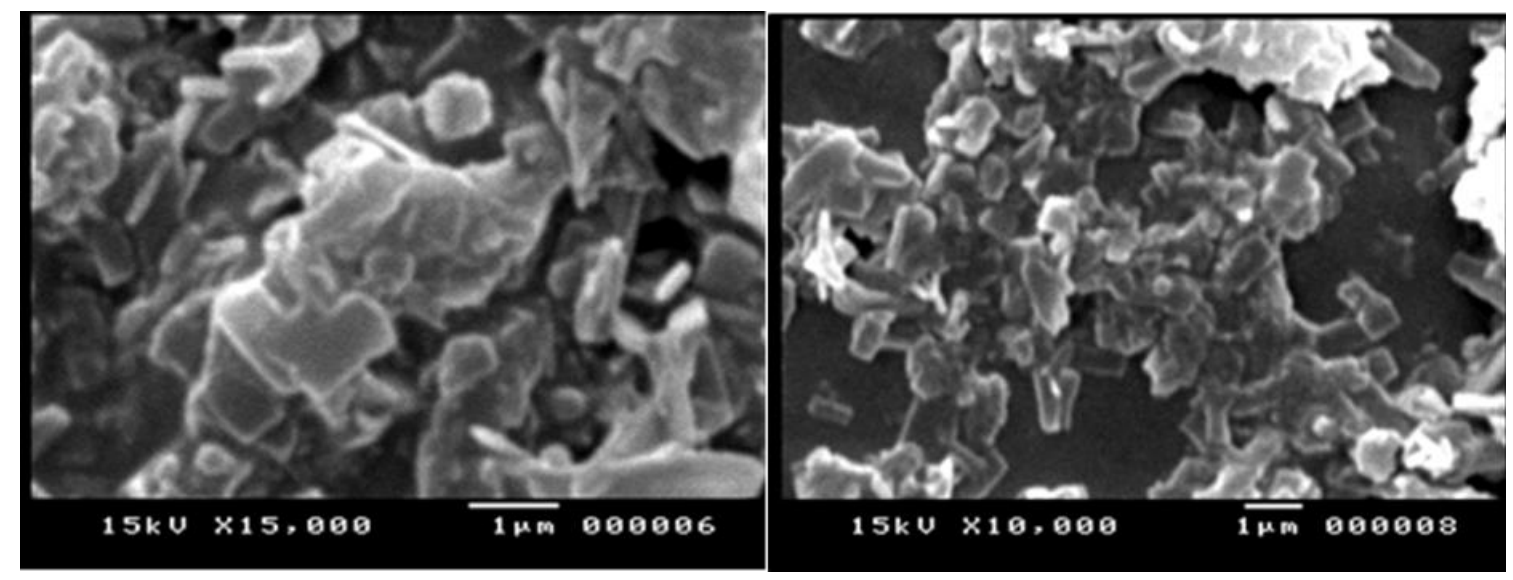

Fig. 1: Scanning electron microscope image of albendazole nanosuspension. 


\section{Lyophilization}

The optimized ALB nanosuspension was subjected to lyophilization procedure to obtain dry nanosuspension, that was then used for further solid phase characterization.

\section{Differential scanning calorimetric studies (DSC)}

DSC thermograms of pure ALB and lyophilized optimized ALB nanosuspension were obtained using thermal analyzer (TA-60, Shimadzu, Japan). Samples were examined in sealed aluminum pans and heated at a constant rate of $10^{\circ} \mathrm{C} / \mathrm{min}$ up to $300^{\circ} \mathrm{C}$ under a nitrogen atmosphere. A similar empty pan was used as a reference.

\section{Fourier Transformed Infrared Spectroscopy (FTIR)}

Infrared spectra of free ALB and lyophilized ALB optimized nanosuspension were recorded using a Nicolet 6700 FT-IR spectrometer (Thermo Fisher Scientific, Waltham, MA).

\section{X-ray diffraction studies (XRD)}

Structure of pure ALB powder and lyophilized ALB nanosuspension were identified using a Philips X-ray diffractometer model PW 1710 (Philips, Amsterdam, The Netherlands) with $\mathrm{CuK} \alpha$ radiation $(\lambda=1.5418$ $\AA$ ), at an operating applied voltage of $40 \mathrm{kV}$ and $30 \mathrm{~mA}$ current, equipped with a graphite monochromator and automatic divergence slit. Scanning rate was maintained at $1^{\circ}$ per min.

\section{Anthelmintic activity of ALB nano- suspension}

Eventually, we studied the anthelmintic activity of the prepared optimized ALB nanosuspension against the Egyptian Earthworm as a representative worm. Twelve worms of approximately equal size were collected and classified randomly into four groups; three worms per group. The studied groups were treated with either, optimized ALB nanosuspension, blank nanosuspension, free ALB powder suspension or distilled water. Earthworms were placed in petri dishes containing $2 \mathrm{ml}$ of each treatment and noticed for about $30 \mathrm{~min}$. The time required for complete paralysis of the worm (worm become motionless) was recorded. The Lethal time was also recorded which was recognized by death of the paralyzed worm followed by body color change ${ }^{2}$.

\section{RESULTS AND DISCUSSION}

\section{Optimization of albendazole nanosuspension using Box-Behnken experimental design}

ALB nanosuspensions were prepared by sono-precipitation method. Three critical factors were considered to affect the studied responses; concentration of lecithin, concentration of PVP and time of the probe sonication. The concentrations of ALB, Pluronic $^{\circledR}$ F68 and volumes of organic and aqueous phases were kept constant for all the prepared formulations. Stabilizers' role is crucial as they prevent agglomeration of the particles and Ostwald ripening to maintain the physical stability of the nanosuspension. Therefore, amount of the added stabilizer is critical and should be optimized as low amount of lecithin might cause aggregation while high amount might end up with Ostwald ripening ${ }^{16 \& 17}$. The preparation process of albendazole nanosuspension was optimized using Box-Behnken experimental design. The design allowed us to obtain 13 different formulations, with a triplication of the central point, resulting in a total of 15 formulations. This replication of the central point allowed to estimate the experimental error ${ }^{14}$. Results of the studied responses; particle size $\left(\mathrm{Y}_{1}\right)$ and PDI $\left(\mathrm{Y}_{2}\right)$, are indexed in table 2. Values of the obtained responses varied from 400 to $1238 \mathrm{~nm}$ for the particle size and from 0.179 to 0.507 for the PDI.

\section{Effect of lecithin concentration}

Particle size $\left(\mathrm{Y}_{1}\right)$ was significantly affected $(p$ value $\leq 0.05)$ with lecithin concentration $\left(\mathrm{X}_{1}\right)$ as expressed in table 3 . The coefficient of the regression analysis presented a positive sign, which means that the particle size increases with an increase in the level of the variable $X_{1}$, which means that, higher concentrations of lecithin generate larger particles. While, lecithin concentration showed insignificant decrease ( $p$ value $\geq 0.05$ ) of the PDI $\left(\mathrm{Y}_{2}\right)$ of the nanosuspension (Table 3). Similar results were obtained by Taneja, Shilpi and Khatri ${ }^{17}$ when they investigated the effect of different concentration of soya lecithin and 
Table 2: Values of the dependent and independent variables and the observed and predicted experimental data for particle size and PDI in each experiment.

\begin{tabular}{|c|c|c|c|c|c|c|c|}
\hline Run & $\begin{array}{c}\mathrm{X}_{1} \\
\text { \% Lecithin } \\
\text { concentration) }\end{array}$ & $\begin{array}{c}\mathrm{X}_{2} \\
\text { (\% PVP } \\
\text { concentration) }\end{array}$ & $\begin{array}{c}\mathrm{X}_{3} \\
\text { (Time, } \\
\text { min.) }\end{array}$ & $\begin{array}{c}\mathrm{Y}_{1} \\
\text { (particle size, } \\
\text { nm) Actual } \\
\text { value }\end{array}$ & $\begin{array}{c}\mathrm{Y}_{1} \\
\text { (particle size, } \\
\text { nm) Predicted } \\
\text { value }\end{array}$ & $\begin{array}{c}\mathrm{Y}_{2} \\
\text { (PDI) } \\
\text { Actual } \\
\text { value }\end{array}$ & $\begin{array}{c}\mathrm{Y}_{2} \\
\text { (PDI) } \\
\text { Predicted } \\
\text { value }\end{array}$ \\
\hline 1 & 0.5 & 0.5 & 10 & 1238 & 1270 & 0.271 & 0.22 \\
\hline 2 & 0.25 & 0.5 & 7 & 1060 & 877.62 & 0.272 & 0.34 \\
\hline 3 & 0.25 & 0.5 & 13 & 853 & 877.62 & 0.204 & 0.22 \\
\hline 4 & 0 & 0 & 10 & 852 & 744.38 & 0.41 & 0.34 \\
\hline 5 & 0 & 0.25 & 7 & 761 & 690.62 & 0.269 & 0.4 \\
\hline 6 & 0.5 & 0.25 & 7 & 766 & 884.62 & 0.202 & 0.28 \\
\hline 7 & 0.5 & 0 & 10 & 1001 & 938.38 & 0.202 & 0.22 \\
\hline 8 & 0 & 0.5 & 10 & 951 & 1076.38 & 0.439 & 0.34 \\
\hline 9 & 0.25 & 0 & 7 & 416 & 545.62 & 0.507 & 0.34 \\
\hline 10 & 0.25 & 0.25 & 10 & 400 & 491.85 & 0.254 & 0.28 \\
\hline 11 & 0.25 & 0.25 & 10 & 496 & 491.85 & 0.286 & 0.28 \\
\hline 12 & 0.25 & 0 & 13 & 505 & 545.62 & 0.198 & 0.22 \\
\hline 13 & 0.5 & 0.25 & 13 & 973 & 884.62 & 0.179 & 0.16 \\
\hline 14 & 0 & 0.25 & 13 & 638 & 690.62 & 0.2 & 0.28 \\
\hline 15 & 0.25 & 0.25 & 10 & 592 & 491.85 & 0.309 & 0.28 \\
\hline
\end{tabular}

Table 3: Analysis of variance results for the considered responses $Y_{1}$ and $Y_{2-\text {. }}$

\begin{tabular}{|c|c|c|c|c|c||}
\hline \multirow{2}{*}{ Factor } & \multicolumn{2}{|c|}{$\mathrm{Y}_{1}$ Particle size } & \multicolumn{2}{c|}{$\mathrm{Y}_{2}$ PDI } \\
\cline { 3 - 6 } & Coefficient & $p$ value & Coefficient & $p$ value \\
\hline \multicolumn{2}{|c|}{ Intercept } & 491.85 & 0.0004 & 0.28 & 0.0477 \\
\hline $\mathrm{X}_{1}$ & Lecithin conc. & 97 & 0.0385 & -0.058 & 0.0711 \\
\hline $\mathrm{X}_{2}$ & PVP conc. & 166 & 0.0022 & - & - \\
\hline $\mathrm{X}_{3}$ & Time & - & - & -0.059 & 0.0685 \\
\hline $\mathrm{X}_{1} \mathrm{X}_{2}$ & - & - & - & - & - \\
\hline $\mathrm{X}_{1} \mathrm{X}_{3}$ & - & - & - & - & - \\
\hline $\mathrm{X}_{2} \mathrm{X}_{3}$ & - & - & - & - & - \\
\hline $\mathrm{X}_{1}{ }^{2}$ & $\mathrm{~A}^{2}$ & 295.77 & 0.0006 & - & - \\
\hline $\mathrm{X}_{2}{ }^{2}$ & $\mathrm{~B}^{2}$ & 219.77 & 0.0043 & - & - \\
\hline $\mathrm{X}_{3}{ }^{2}$ & - & - & - & - & - \\
\hline \hline
\end{tabular}

Note: $p$-values were $\leq 0.05$, with a $95 \%$ confidence interval. Abbreviations: PDI, polydispersity index.

poloxamer 407 on the particle size of the prepared efavirenz nanosuspension and they reported that concentration as low as $0.1 \%$ showed higher particle size $(892.6 \mathrm{~nm})$ while concentration of $0.5 \%$, produced particle size of $359.8 \mathrm{~nm}$. The optimum particle size was obtained using $0.3 \%$ of both stabilizers $(182.4$ $\mathrm{nm})$.

\section{Effect of PVP concentration}

As illustrated in table 3, PVP concentration $\left(\mathrm{X}_{2}\right)$ affected only the particle size $\left(\mathrm{Y}_{1}\right)$ significantly ( $p$ value $\leq 0.05$ ) while has no effect on PDI. Regression coefficient exhibited a positive sign which indicates that with increasing the concentration of PVP, the nanosuspension particle size increases. The 
non-ionic surfactant, PVP, could be attached to the surface of drug particles, prevent drug particles from interaction and provide steric stabilization between particles. Therefore, its concentration should be adjusted, since using low PVP concentration might led to crystals growth and agglomeration while increasing its concentration above a certain limit, increased the particle size due to the formation of a thick layer on their surface ${ }^{18}$. Another study reported similar results, as increasing ration of drug: PVP-K30 from $1: 1$ to $1: 2$, decreased the particle size of the prepared Ibuprofen nanosuspensions while further increase of PVP-K30 ratio to $1: 3$, resulted in higher particle size ${ }^{19}$.

\section{Effect of time for probe-sonication}

The effect of the probe-sonication time $\left(\mathrm{X}_{3}\right)$ on the dependent variables is shown in table 3. This factor has neither influence on nanoparticles' size $\left(\mathrm{Y}_{1}\right)$ nor on the PDI $\left(\mathrm{Y}_{2}\right)$ since the $p$ values were $\geq 0.05$. It means that the studied responses are not affected with the studied different sonication time.

The mathematical relationship in the form of polynomial equations 1 and 2 were generated by the Design-Expert ${ }^{\circledR} 8.0$ software for the measured responses; particle size and PDI.
$\mathrm{Y}_{1}($ Particle size $)=491.85+97 * \mathrm{~A}+166 * \mathrm{~B}+$ $295.77 * \mathrm{~A}^{2}+219.77 * \mathrm{~B}^{2}$ equation 1

$\mathrm{Y}_{2}(\mathrm{PDI})=0.28-0.059 * \mathrm{~A}-0.059 * \mathrm{C}$ equation 2

Where: A is lecithin concentration, $\mathrm{B}$ is PVP concentration and $\mathrm{C}$ is the probe sonication time. $\mathrm{A}, \mathrm{B}$ and $\mathrm{C}$ are linear terms. $\mathrm{A}^{2}, \mathrm{~B}^{2}$ and $\mathrm{C}^{2}$ are Quadratic terms. The intercept corresponds to the mean of the responses. The magnitude of coefficients in polynomial equation has either a positive sign, indicating synergistic effect, or a negative sign, indicating antagonistic effect.

As the studied responses of the nanosuspensions were affected with the formulation parameters, a statistically mathematical polynomial model was fitted among the linear, two-factor $(2 \mathrm{~F})$ interaction and quadratic model based on the analysis of multiple correlation coefficient R-squared, predicted R-squared, and adjusted R-squared which were used to identify the optimal model where the suggested model focus on maximizing the adjusted and predicted Rsquares (Table 4). Quadratic model was suggested for particles size $\left(\mathrm{Y}_{1}\right)$ due to the highest $r^{2}$ values while for PDI $\left(\mathrm{Y}_{2}\right)$, linear model was suggested.

Table 4: Results of model summary statistics analysis for responses.

\begin{tabular}{||c|c|c|c|c|c|c||}
\hline \multirow{2}{*}{ Model } & \multicolumn{3}{|c|}{$\mathrm{Y}_{1}$} & \multicolumn{3}{c||}{$\mathrm{Y}_{2}$} \\
\cline { 2 - 7 } & R-square & $\begin{array}{l}\text { Adjusted } \\
\text { R-square }\end{array}$ & $\begin{array}{l}\text { Predicted } \\
\text { R-square }\end{array}$ & R-square & $\begin{array}{l}\text { Adjusted } \\
\text { R-square }\end{array}$ & $\begin{array}{l}\text { Predicted } \\
\text { R-square }\end{array}$ \\
\hline Linear & 0.3285 & 0.1454 & -0.175 & $\mathbf{0 . 4 1 3 4}$ & $\mathbf{0 . 2 5 3 4}$ & $\mathbf{- 0 . 2 4 5}$ \\
\hline 2FI & 0.3883 & -0.0704 & -1.1514 & 0.5263 & 0.1711 & -1.4751 \\
\hline Quadratic & $\mathbf{0 . 9 1 2 9}$ & $\mathbf{0 . 7 5 6}$ & $\mathbf{- 0 . 1 1 2 8}$ & 0.7411 & 0.2752 & -2.9886 \\
\hline
\end{tabular}

Bold refer to the suggested model that focus on the model maximizing the adjusted and predicted R-squared. 


\section{Response surface analysis}

The effect of the independent variables (lecithin concentration $\left(\mathrm{X}_{1}\right)$ and PVP concentration $\left(\mathrm{X}_{2}\right)$ ) on the particle size $\left(\mathrm{Y}_{1}\right)$ as a dependent variable was studied using DesignExpert $^{\circledR}$ software. The response surface was plotted as three-dimensional (3D) plot and twodimensional (2D) contour plot in figure 2 where the effect of lecithin and PVP concentrations on the nanosuspension particle size are presented at a fixed sonication time (10 min.).

\section{Optimization and validation of ALB nanosuspension using box-behnken design}

To obtain the optimum formulation of albendazole nanosuspension with the most desirable characteristics, additional optimization and validation processes were developed by Design-Expert ${ }^{\circledR}$ software, depending on a predetermined desirable criterion of a minimum values for both the particle size and PDI. Based on the software optimization, the formulation with highest desirability (0.834) was selected as the optimized formulation with values for $\mathrm{X}_{1}$ (lecithin concentration), $\mathrm{X}_{2} \quad$ (PVP concentration) and $\mathrm{X}_{3}$ (probe sonication time) were $0.238 \%, 0.156 \%$ and $13 \mathrm{~min}$. respectively, which gave theoretical values of $456.47 \mathrm{~nm}$ particle size and 0.224 for PDI. Therefore, in order to confirm the predicted model, a new batch of ALB nanosuspension was prepared according to the optimal formulation factor levels. The observed values for the prepared optimized formulation were $516.6 \mathrm{~nm}$ for particle size and 0.289 for PDI, which were $88.36 \%$ of the predicted values.

\section{Characterization of the optimized nano- suspension}

Improvement of solubility of the poorly water-soluble drugs as albendazole is important to enhance its bioavailability and activity. We investigated the solubility of ALB nanosuspension compared to ALB pure powder in phosphate buffer ( $\mathrm{pH}$ 7.4). Studies have demonstrated a dramatic increase in ALB solubility, approximately 10 - fold increase (115 $\mu \mathrm{g} / \mathrm{ml}$ for ALB nanosuspension and $12 \mu \mathrm{g} / \mathrm{ml}$ for pure ALB powder). Differential scanning calorimetric thermograms of pure ALB and
ALB nanosuspension are shown in figure 3 . Pure ALB powder showed a sharp endothermic peak at $195^{\circ} \mathrm{C}$, indicating the melting of albendazole while this peak was disappeared in the peak of the lyophilized ALB nanosuspension. This indicates the interaction between albendazole, and the polymers used in preparation of the nanosuspension. That was confirmed also by X-ray diffraction patterns of pure ALB and ALB nanosuspension that is presented in figure 4. The diffractogram of pure ALB shows characteristic peaks at $2 \Theta$ around $7.3^{\circ}, 11.8^{\circ}, 20.4^{\circ}$, and $24.7^{\circ}$ which indicates its crystalline nature ${ }^{20}$. However, some peaks disappeared in the case of ALB nanosuspension which indicate the transformation of ALB from the crystalline form to amorphous form by formulation of nanosuspension of the drug using the studied polymers. Transformation of the drug from the crystalline state into the amorphous state provides a high-energy state and high disorder, which in turn results in enhancing solubility and dissolution rate ${ }^{21}$. These results are in a good agreement with those obtained from the previously mentioned solubility study of pure ALB and ALB nanosuspension. The infrared spectra of pure ALB and lyophilized ALB nanosuspension are presented in figure 5. Albendazole characteristic peaks are of 1096, 1634, 1713, 2957 and $3303 \mathrm{~cm}^{-1}$ which corresponds to $\mathrm{C}-\mathrm{O} / \mathrm{C}-\mathrm{S}$ stretching, aromatic ring stretch, primary amide band, $\mathrm{C}-\mathrm{H}$ stretch and $\mathrm{N}-\mathrm{H}$ stretching, respectively ${ }^{22}$. As observed in figure 4 , there is no major shifting of the functional peaks between the spectra of the drug and drug nanosuspension. Eventually, we assessed the Anthelmintic activity of the prepared optimized ALB nanosuspension against earth worms as a representative worm. Worms were observed, and paralysis and/or death times were calculated for the different groups treated with ALB nanosuspension, blank nanosuspension, pure ALB suspension and water. As illustrated in table 5 and figure 6 , ALB nanosuspension-treated group $(2 \mathrm{mg} / \mathrm{ml})$ exhibited superior activity where paralysis of worm occurred within one min. while complete death was noticed within three min. While, pure ALB suspension, worms were paralyzed after $30 \mathrm{~min}$. 

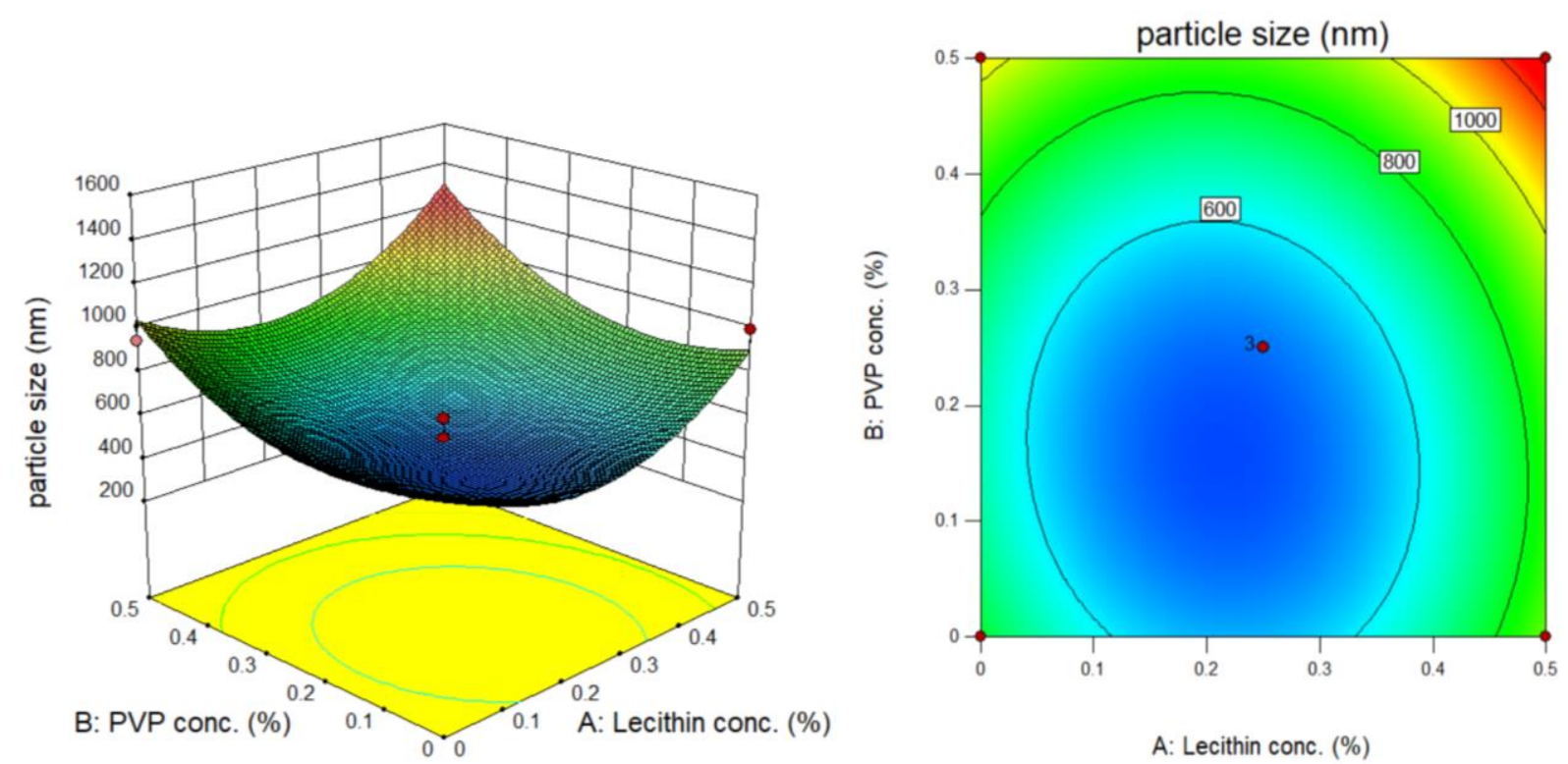

A: Lecithin conc. (\%)

Fig. 2: Three-dimensional (3D) response surface plot (left figure) and two-dimensional (2D) contour plot (right figure) showing the effect of the independent variables (PVP and lecithin concentrations) on the particle size.

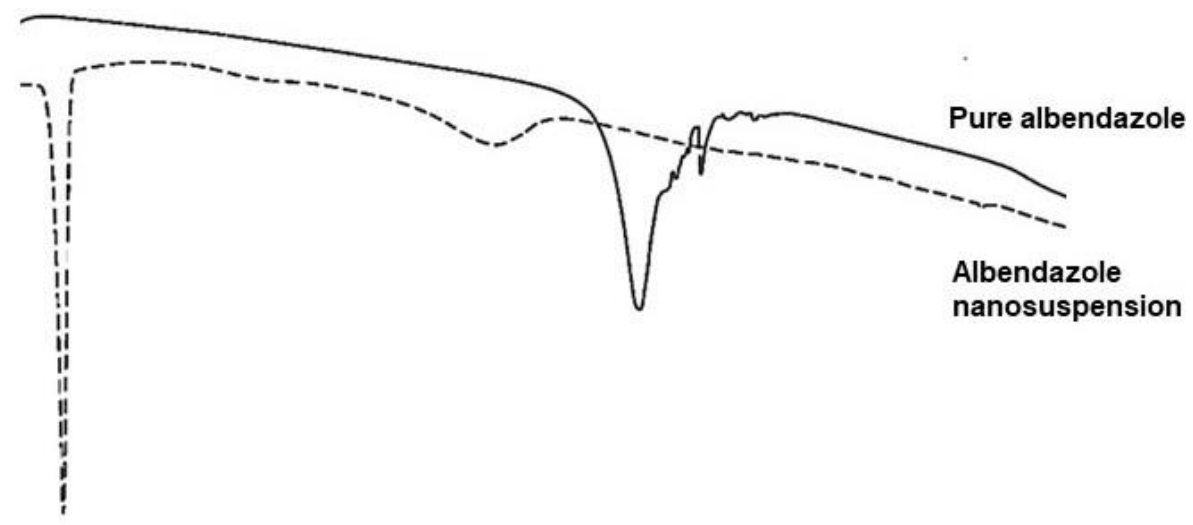

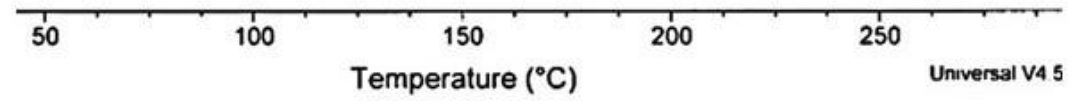

Fig. 3: Differential scanning calorimetry thermograms of pure albendazole (solid line) and lyophilized albendazole nanosuspension (dotted line). 


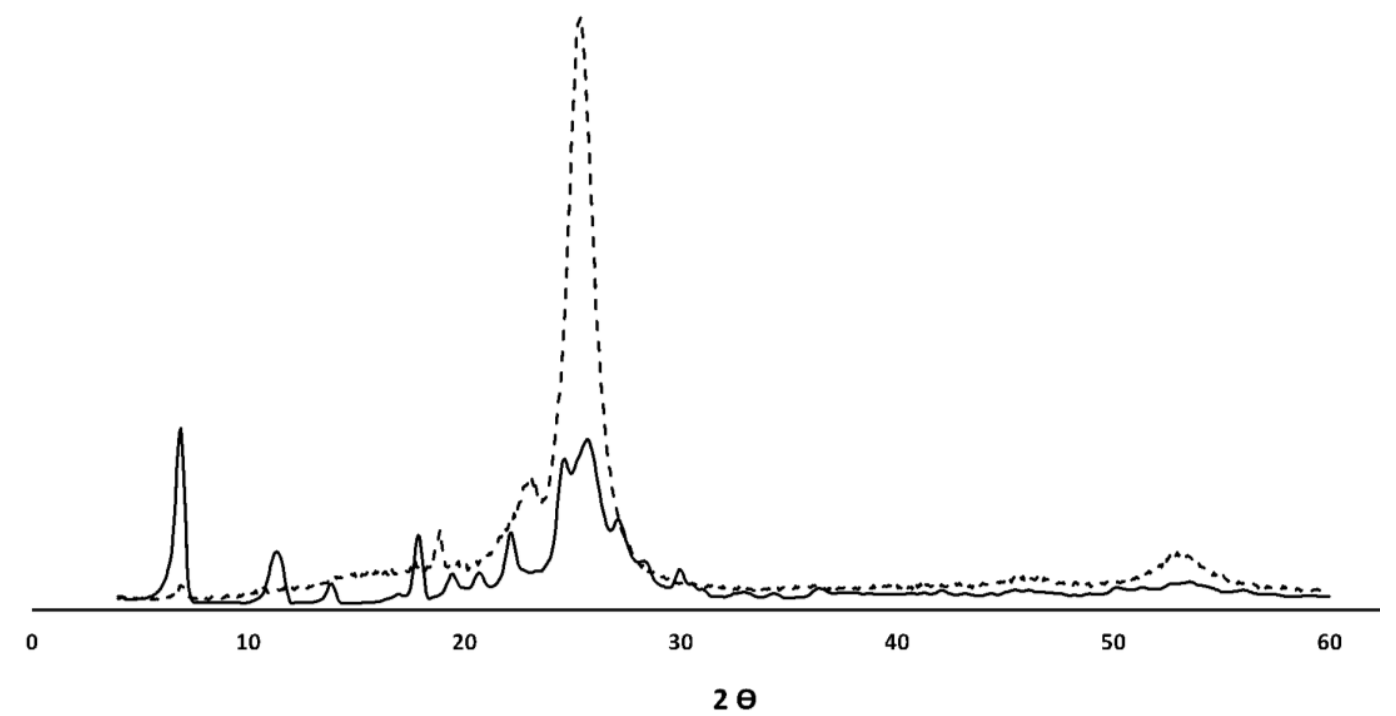

Fig. 4: X-ray diffraction pattern of pure albendazole (solid line) and lyophilized albendazole nanosuspension (dotted line).

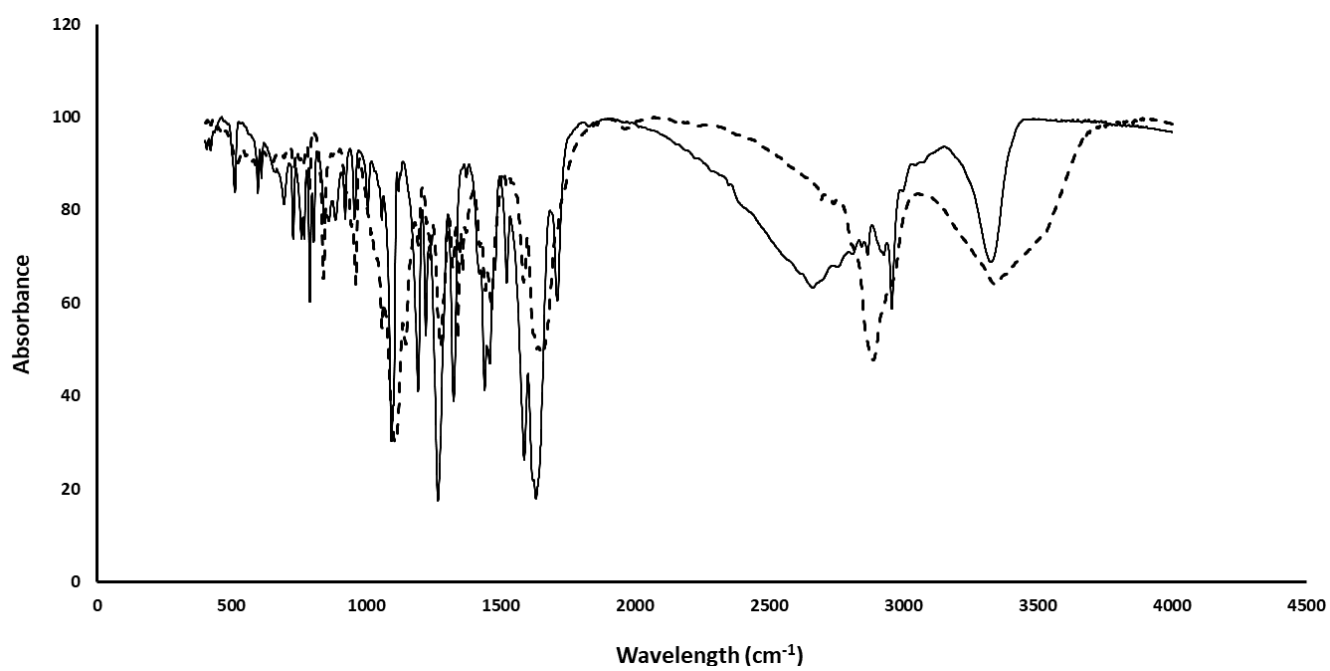

Fig. 5: FTIR of pure albendazole (solid line) and lyophilized albendazole nanosuspension (dotted line).

Table 5: Anthelmintic activity of albendazole against earth worms.

\begin{tabular}{||c|c|c|c|c||}
\hline & $\begin{array}{c}\text { Albendazole } \\
\text { nanosuspension }\end{array}$ & $\begin{array}{c}\text { Blank } \\
\text { nanosuspension }\end{array}$ & $\begin{array}{c}\text { Albendazole } \\
\text { suspension }\end{array}$ & Control \\
\hline $\begin{array}{c}\text { Paralysis time } \\
\text { (min.) }\end{array}$ & 1 & 8 & 30 & - \\
\hline $\begin{array}{c}\text { Death time } \\
\text { (min.) }\end{array}$ & 3 & 10 & - & - \\
\hline
\end{tabular}




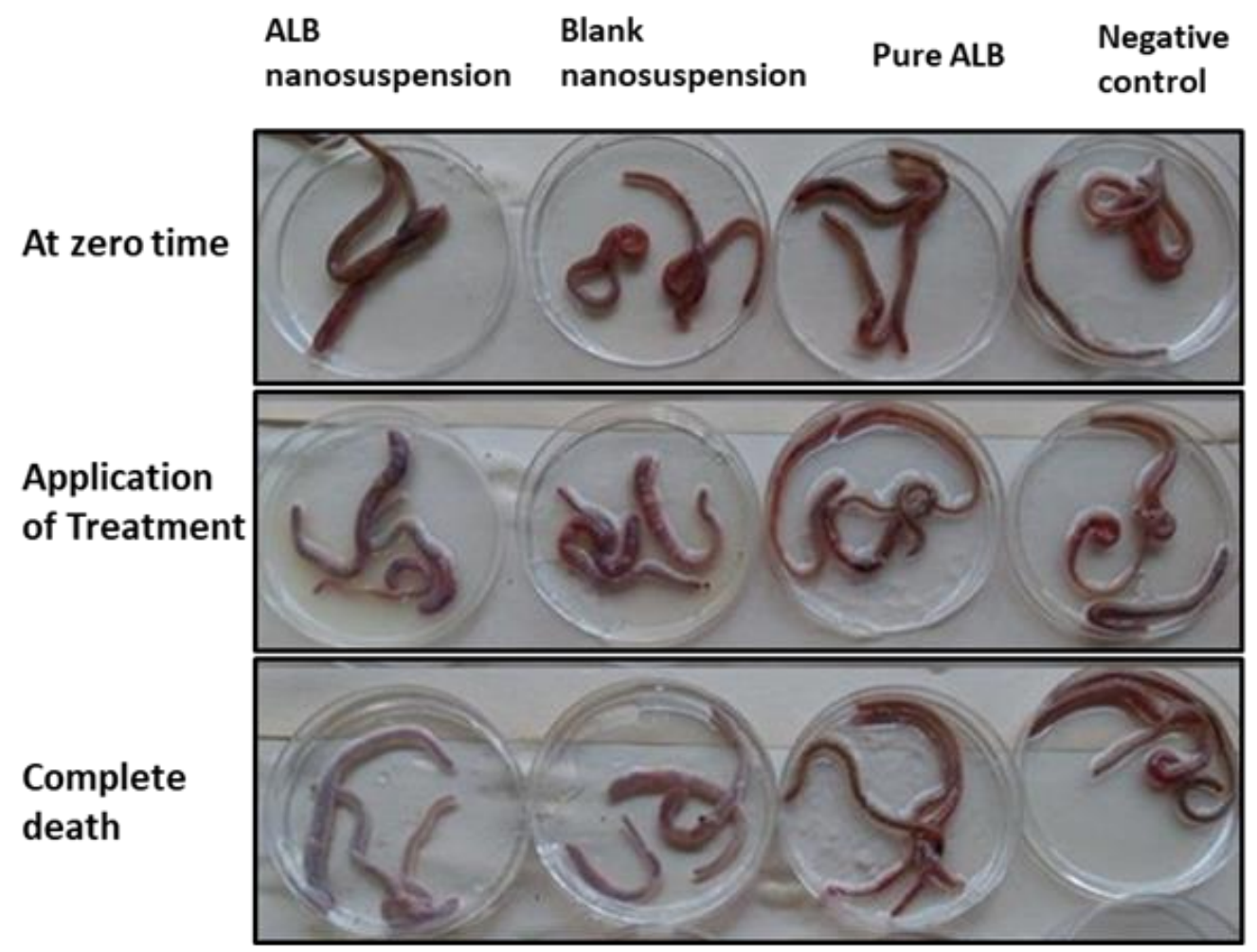

Fig. 6: Anthelmintic activity of albendazole nanosuspension, blank nanosuspension, albendazole pure suspension and negative control (distilled water).

Each group contains three worms of equal size earthworms.

\section{Conclusion}

Nanosuspension of albendazole was successfully prepared and characterized using sono-precipitation method. Stabilizers and surfactants should be added at optimal concentrations in order to produce a suitable nanosuspension with appropriate size. As the size of nanosuspension is an important factor in the solubility and bioavailability of the drug and depends on many factors, therefore it could be optimized using box-behnken design. The study showed that particle size was increased by increasing lecithin and PVP concentrations while probe-sonication time had no influence on the size. Albendazole nanosuspension exhibited higher solubility ( 10 folds) than pure albendazole powder. consequently, ALB nanosuspension showed enhanced anthelmintic activity (short paralysis and death time) against earth worm (representative worm) compared to free ALB suspension. Therefore, topical application of an optimized ALB nanosuspension with better bioavailability could be a beneficial local adjuvant therapy for the oral anthelmintic drugs since it reliefs the itching in the anal area that could not be immediately relieved by the oral treatment only.

\section{REFERENCES}

1- K. Pillai, J. Akhter and D.L. Morris, "Super aqueous solubility of albendazole in $\beta$-cyclodextrin for parenteral application in cancer therapy", J. Cancer, 8 (6), 913-923 (2017).

2- K. D. Koradia, R. H. Parikh and H. D. Koradia, "Albendazole nanocrystals: Optimization, spectroscopic, thermal and anthelmintic studies", J. Drug Deliv. Sci. Technol., 43, 369-378 (2018).

3- E. Brunetti, P. Kern and D.A. Vuitton, "Expert consensus for the diagnosis and treatment of cystic and alveolar echinococcosis in humans", Acta Trop., 114, 1-16 (2010).

4- F. K. Alanazi, M. EL-Badry, M. O. Ahmed and I. A. Alsarra, "Improvement of albendazole dissolution by preparing microparticles using spray-drying technique", Sci. Pharm., 75, 63 (2007). 
5- L. Martinez Marcos, D. A. Lamprou, R. T. McBurney and G. W. Halbert, "A novel hot-melt extrusion formulation of albendazole for increasing dissolution properties", Int. J. Pharm., 499, 175-185 (2016).

6- B. Pradines, J-F. Gallard, B. I. Iorga, C. Gueutin, P. M. Loiseau, G. Ponchel and K. Bouchema, "Investigation of the complexation of albendazole with cyclodextrins for the design of new antiparasitic formulations", Carbohydr. Res., 398, 50-55 (2014).

7- S. Sawatdee, A. Atipairin, A. Sae Yoon, T. Srichana, N. Changsan and T. Suwandecha, "Formulation development of albendazole-loaded self-microemulsifying chewable tablets to enhance dissolution and bioavailability", Pharmaceutics, 11 (3), 134-154 (2019).

8- R. Yadollahi, K. Vasilev and S. Simovic, "Nanosuspension technologies for delivery of poorly soluble drugs", $\boldsymbol{J}$. Nanomater., 2015, Article ID 216375 (2015).

9- J. Hao, Y. Gao, J. Zhao, J. Zhang, Q. Li., Z. Zhao and J. Liu, "Preparation and optimization of resveratrol nanosuspensions by antisolvent precipitation using Box-Behnken design", AAPS PharmSciTech., 16, 118-128 (2014).

10- V. B. Patravale, A. A. Date and R. M. Kulkarni, "Nanosuspensions: A promising drug delivery strategy", J. Pharm. Pharmacol., 56, 827-840 (2004).

11- H.-R. Lin, C. C. Tseng, Y. J. Lin and M. H. Ling, "A novel in-situ-gelling liquid suppository for site-targeting delivery of anti-colorectal cancer drugs", J. Biomater. Sci., 23 (6), 807-822 (2012).

12- I. M. Rigter, H. G. Schipper, R. P. Koopmans,H. J. M. van Kan, H. W. Frijlink, P. A. Kager and H.-J. Guchelaar, "Relative bioavailability of three newly developed albendazole formulations: A randomized crossover study with healthy volunteers", Antimicrob. Agents Chemother., 48 (3), 1051-1054 (2004).

13- S. Singh, C. Panda, N. Rout, et al., "Anal albendazole application for pruritus ani in threadworm infestation", J. Trop. Pediatr., 51, 368 (2005).

14- A. C. Vieira, L. L. Chaves, M. Pinheiro, D. Ferreira, B. Sarmento and S. Reis, "Design and statistical modeling of mannose-decorated dapsone-containing nanoparticles as a strategy of targeting intestinal M-cells", Int. J. Nanomedicine, 11, 2601-2617 (2016).

15- K. Nagaraj, D. Narendar and V. Kishan, "Development of olmesartan medoxomil optimized nanosuspension using the BoxBehnken design to improve oral bioavailability", Drug Dev. Ind. Pharm., 43, 1186-1196 (2017).

16- A. Karakucuk and N. Celebi, "Investigation of formulation and process parameters of wet media milling to develop etodolac nanosuspensions", Pharm. Res., 37, 111 (2020).

17- S. Taneja, S. Shilpi and K. Khatri, "Formulation and optimization of efavirenz nanosuspensions using the precipitation-ultrasonication technique for solubility enhancement", Artif. Cells Nanomed. Biotechnol., 44, 978-984 (2016).

18- D. H. Kuk, E. S. Ha, D. H. Ha, W. Y. Sim, S. K. Lee, J. S. Jeong, J. S. Kim, I. Baek, H. Park, D. H. Choi, J. W. Yoo, S. H. Jeong, S. J. Hwangand and M. S. Kim, "Development of a resveratrol nanosuspension using the antisolvent precipitation method without solvent removal, based on a quality by design (QbD) approach", Pharmaceutics, 11 (12), 688-710 (2019).

19- A. Nada, F. Bandarkar and Y. AlBasaraha, "Formulation of ibuprofen nanoparticles and nanosuspensions with enhanced dissolution rate using ultra homogenization technique", Asian $J$. Pharm., (Suppl) 11 (1), S14 (2017).

20- N. C. T. Cavalcanti, G. D. Sousa, M. A. M. Tabosa, J. L. S. Sobrinho, L. B. Leal and D. P. de Santana, "Assay and physicochemical characterization of the antiparasitic albendazole", Braz. J. Pharm. Sci., 48, 281-290 (2012).

21- D.-H. Won, M.-S. Kim, S. Lee, J.-S. Park and S.-J. Hwang, "Improved physicochemical characteristics of felodipine solid dispersion particles by supercritical anti-solvent precipitation process", Int. J. Pharm., 301, 199-208 (2005).

22- S. Gunasekaran and D. Uthra, "Vibrational spectra and qualitative analysis of albendazole and mebendazole", Asian J. Chem., 20 (8), 6310-6324 (2008). 


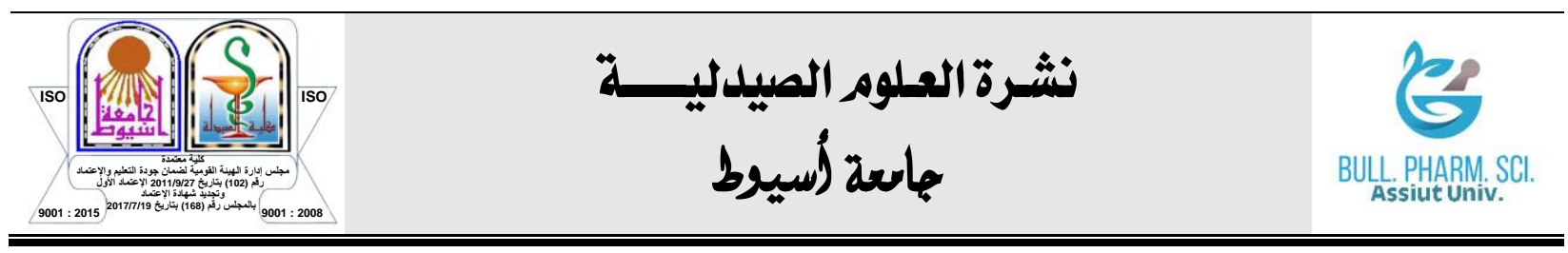

\section{تخليق وتحسين صياغات تعليق نانومترية لعقار الألبيندازول كعلاج تكميلى موضعي

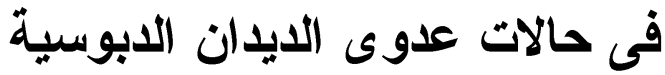

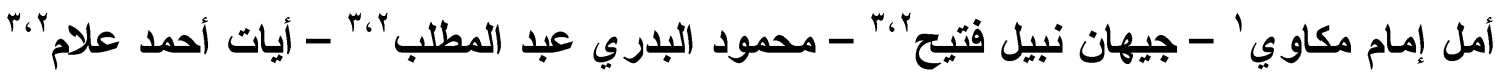
'قسم الصيدلانيات والصيدلة الإكلينيكية ، كلية الصيدلة ، جامعة سوهاج ، سوهاج ، مصر

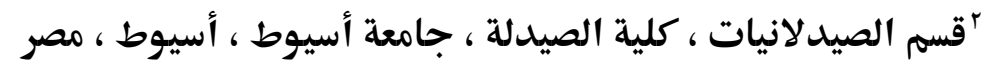

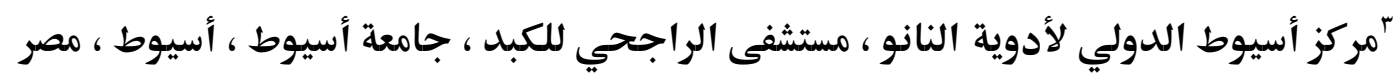

تهدف الدراسة الحالية إلى تحضير صياغات من عقار الألبيندازول فى شكل معلق نـانومترى إنـاني

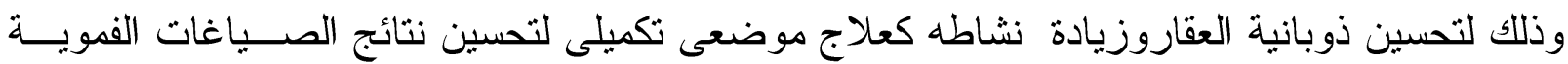

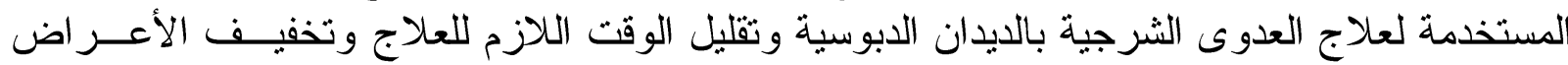

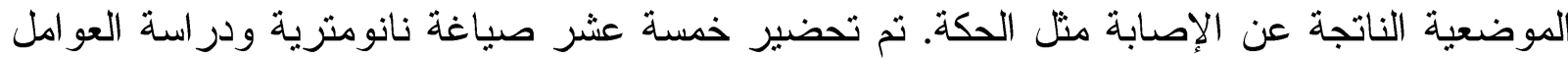

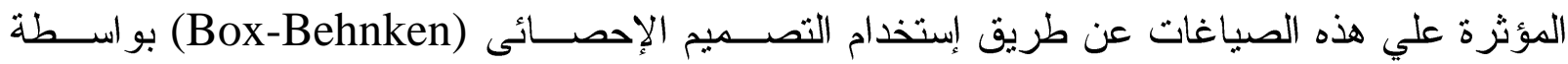

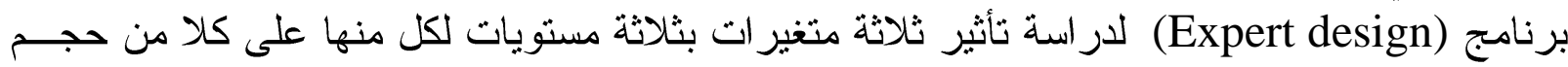

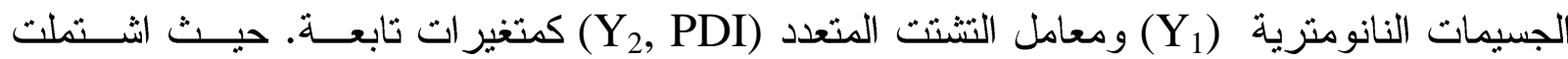

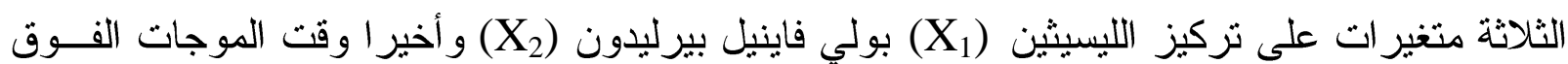
الصوتية (X3) المستخدم فى تحضير الصياغات النانو مترية.

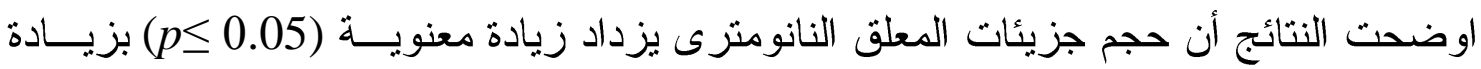

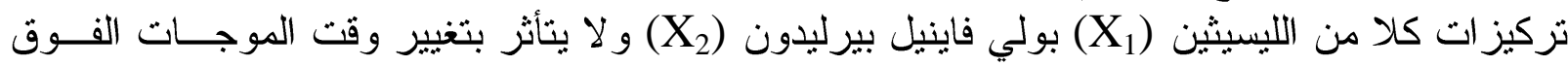

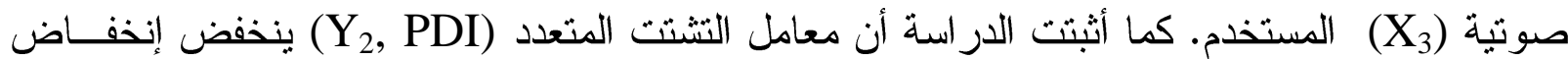

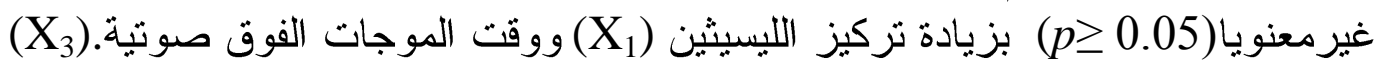

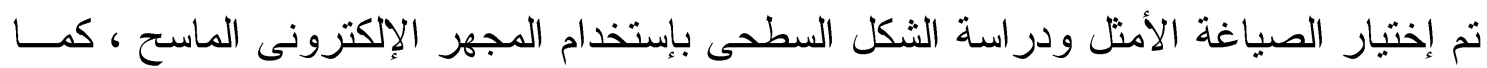

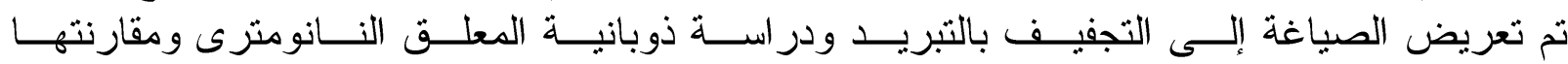

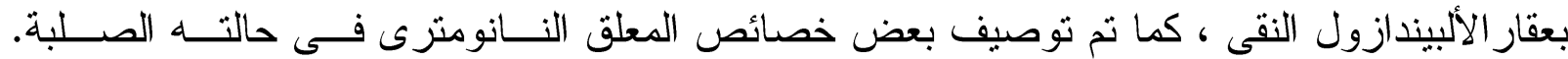

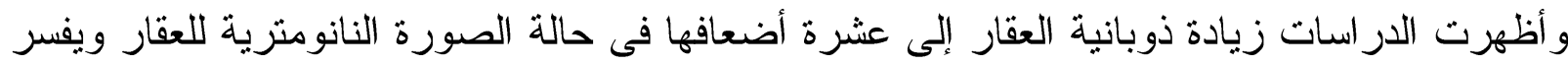

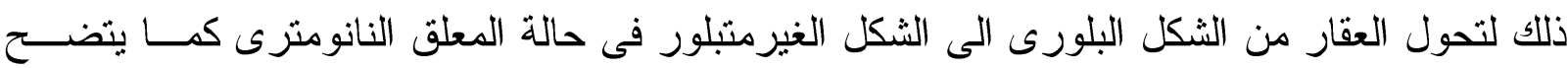

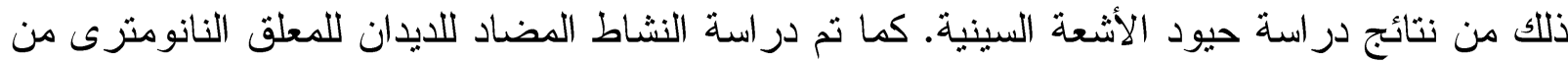

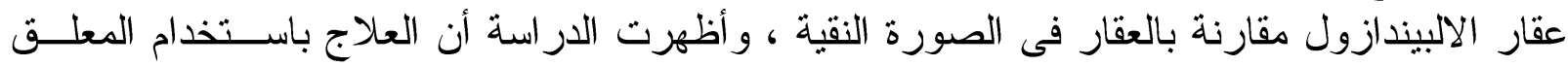

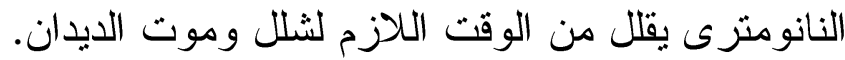

